\title{
The Comparison of Conventional and Retzius-Sparing Robot-Assisted Radical Prostatectomy for Clinical, Pathological, and Oncological Outcomes
}

\author{
(1) Nejdet Karşıyakalı1, (1) Mahir Bülent Özgen1, (1) Bora Özveren11, (1) Haydar Durak2, (1) Yeşim Sağlıcan33 (1) Levent Türkeri1 \\ ${ }^{1}$ Acıbadem Mehmet Ali Aydınlar University, Altunizade Hospital, Clinic of Urology, Istanbul, Turkiye \\ ${ }^{2}$ Acıbadem Mehmet Ali Aydınlar University, Altunizade Hospital, Clinical Pathology Laboratory, İstanbul, Turkiye \\ ${ }^{3}$ Acıbadem Mehmet Ali Aydınlar University, Maslak Hospital, Clinic of Pathology, İstanbul, Turkiye
}

\section{What's known on the subject? and What does the study add?}

Initial description of the surgical technique involves the dissection of the Retzius space after dropping the bladder from the anterior abdominal wall which is now considered as the "conventional" method of robot-assisted radical prostatectomy (cRARP). Retzius-sparing RARP (RsRARP; Bocciardi approach) was initially introduced by Galfano et al. in 2010 and it is one of the most innovative surgical approaches which allows preservation of deep dorsal venous complex and anatomical structures responsible for urinary continence such as urinary sphincter, endopelvic fascia, and puboprostatic ligaments. RsRARP appears to have superior early continence recovery and similar oncologic outcomes when compared to cRARP. Studies of direct comparison of cRARP with RsRARP in the hands of the same surgeon(s) are still limited. In this study we presented our single-center, single-surgeon, long-term experience by comparing cRARP and RsRARP in terms of perioperative clinical, pathological, and oncological outcomes. One of the main emerging findings of this study was a shorter surgical time with RsRARP. RsRARP becomes prominent with a shorter surgery duration and similar complication rates when compared to cRARP in patients with higher ASA class scores even if they had higher cT stages and D'Amico clinical risk group in the preoperative evaluation indicating a safe surgical approach.

\section{Abstract}

Objective: This study aimed to assess and compare the conventional and Retzius-sparing robot-assisted radical prostatectomy (cRARP and RsRARP) in term of perioperative clinical, pathological, and oncological outcomes.

Materials and Methods: This study included 238 consecutive male patients who underwent RARP between May 2008 and November 2020. RARP operations were performed by a single-surgeon. Patients were divided into groups according to the surgical approach and were statistically compared in terms of perioperative clinical, final pathological, and oncological outcomes.

Results: The mean age of patients was $64 \pm 7$ years. cRARP was performed in 134 (56.3\%) patients, whereas RsRARP in 104 (43.7\%). The frequency of patients with the American Society of Anesthesiologists Class-2 score was higher in the RsRARP group ( $<<0.001)$. The median surgery duration was 300 (270-360) min. The median surgery duration was shorter in RsRARP group (290 vs. 330 minute) ( $<<0.001)$. No difference was found between the groups in terms of estimated blood loss and postoperative complication rates ( $p=0.112$ and $p=0.182$, respectively). No difference was found between the groups when they were compared for surgical margin positivity ( $p=0.453$ ). Although not statistically significant, the frequency of surgical margin positivity with $\mathrm{pT3a} / \mathrm{pT3}$ disease was higher in patients who underwent cRARP ( $p=0.412$ and $p=0.261$, respectively). At a median follow-up of 13 (6-36) months, no difference was found between the groups in terms of biochemical recurrence at months $-3,-6,-9,-12,-18,-24$, and -30 , respectively ( $p>0.05$, for each).

Conclusion: RsRARP allows a safe operation with a shorter surgical time and similar surgical margin positivity, oncological outcomes, and complication rates compared to cRARP.

Keywords: Retzius-sparing, robot-assisted radical prostatectomy, radical prostatectomy, robotics, prostate cancer

Correspondence: Nejdet Karşıyakalı MD, Acıbadem Mehmet Ali Aydınlar University, Altunizade Hospital, Clinic of Urology, İstanbul, Turkiye Phone: +90 5058652463 E-mail: nkarsiyakali@hotmail.com ORCID-ID: orcid.org/0000-0002-0709-0331

Received: 04.04 .2021 Accepted: 14.05 .2021

Cite this article as: Karşıyakalı N, Özgen MB, Özveren B, Durak H, Sağlıcan Y, Türkeri L. The Comparison of Conventional and Retzius-Sparing Robot-Assisted Radical Prostatectomy for Clinical, Pathological, and Oncological Outcomes. J Urol Surg, 2022;9(1):1-8.

๑Copyright 2022 by the Association of Urological Surgery / Journal of Urological Surgery published by Galenos Publishing House. 


\section{Introduction}

Radical prostatectomy (RP) is the recommended definitive surgical treatment modality for patients who had organconfined prostate cancer ( $\mathrm{PCa}$ ) and are eligible for radical surgery with a life expectancy of at least 10 years (1). In 2000, robot-assisted RP (RARP) was reported for the first time as a consequence of technological advances in the field of medicine $(2,3)$. Subsequent experience identified RARP as a minimally invasive surgical technique with proven advantages, such as reduced perioperative bleeding and blood transfusion, reduced postoperative pain, and reduced length of hospital stay compared to open RP $(4,5)$. The initial description of the surgical technique involves the dissection of the Retzius space after dropping the bladder from the anterior abdominal wall, which is now considered as the "conventional" method of RARP (cRARP) $(3,6)$. Several modifications in the surgical technique, such as restoration of the posterior aspect of rhabdosphincter, periurethral suspension stitch, total anatomic reconstruction, etc., were described to provide better functional outcomes (7-9). Retzius-sparing RARP (RsRARP; Bocciardi approach) was initially introduced by Galfano et al. (10) in 2010 and is one of the most innovative surgical approaches, which preserves the deep dorsal venous complex and anatomical structures responsible for urinary continence, such as urinary sphincter, endopelvic fascia, and puboprostatic ligaments.

Subsequent studies revealed that RsRARP has superior early continence recovery and similar oncologic outcomes compared to cRARP (11-14). However, studies that directly compare cRARP with RsRARP in the hands of the same surgeon(s) are still limited. Therefore, this study aimed to present our single-center, single-surgeon, and long-term experience by comparing cRARP and RsRARP in terms of perioperative clinical, pathological, and oncological outcomes to contribute to the cumulative body of knowledge on this topic.

\section{Materials and Methods}

\section{Study Population and Surgical Approach}

We retrospectively reviewed the medical records of male patients who underwent PCa surgery in Acıbadem Mehmet Ali Aydınlar University, Altunizade and Kadiköy Hospitals, Clinics of Urology between May 2008 and November 2020. The study included patients who were diagnosed with PCa and treated with RARP and with sufficient clinical information in their medical records. The Local Institutional Ethics Committee (IRB No: 2020-26/09) approved this study and all steps were planned and conducted following the Declaration of Helsinki and its later amendments. Written informed consent on admittance to the hospital was obtained from all individuals, which permitted the use of respective medical information in clinical studies.

Demographic and preoperative clinical characteristics of patients, perioperative surgical parameters, such as duration of surgery, estimated blood loss, postoperative complications according to the Clavien-Dindo (C-D) surgical complication classification (15), length of hospital stay, and catheterization duration, as well as pathological findings of both prostate biopsy and prostatectomy specimens, were recorded in detail for each patient. Clinically significant PCa was defined as the presence of the Gleason score of $>6$ or Gleason score of 6 diseases and tumor volume $>0.5 \mathrm{~cm}^{3}$ for prostatectomy specimens as previously reported by Epstein et al. (16). Prostate-specific antigen (PSA) levels were recorded for patients who continued their outpatient clinic follow-ups. Biochemical recurrence (BCR) was defined as PSA levels of $0.2 \mathrm{ng} / \mathrm{mL}$ or higher, which was confirmed by a repeat measurement at 2 weeks.

Patients who underwent open RP ( $n=3)$, whose Gleason score could not be evaluated in prostatectomy specimen due to neoadjuvant docetaxel chemotherapy $(n=2)$, and those with missing clinical data $(n=20)$ were excluded from the study. Patients were divided into two groups according to the surgical approach (cRARP and RsRARP groups).

A single-surgeon (L.T.) with experience in robotic surgery performed all RARP operations using DaVinci ${ }^{\circ}$ Si or Xi Surgical Systems (Intuitive Surgical, Sunnyvale, CA, USA). cRARP operations were performed as previously described by Rocco et al. (7), while RsRARP operations were performed as described by Galfano et al. (10), with minor modifications in both operations. During RsRARP, the selection of fascial planes for dissection and transition from one plane to another was performed based on preoperative imaging and anatomical findings during surgery to achieve negative surgical margins. The surgical duration was described as the time interval between the first trocar insertion and suture closure of the last port site. All prostatectomy specimens were evaluated by two dedicated uro-pathologists (H.D. \& Y.S.) following the latest International Society of Urologic Pathology (ISUP) criteria (17).

\section{Statistical Analysis}

Statistical analysis was performed using the Statistical Package for the Social Sciences version 22.0 software (IBM Corp., Armonk, NY, USA). The Kolmogorov-Smirnov and Shapiro-Wilk tests were used to check the normality of data for quantitative variables. Continuous variables were expressed in mean \pm standard deviation and median and interquartile range, whereas categorical variables were expressed in number and frequency. The Pearson chi-square, Fisher Exact, Student t-test, and MannWhitney $\mathrm{U}$ tests were used wherever possible. A two-sided $p$-value of $<0.05$ was considered statistically significant. 


\section{Results}

This study included 238 male patients. The mean age of patients was $64 \pm 7$ years and the mean prostate volume was $52.34 \pm 22.55$ $\mathrm{mL}$. The median preoperative PSA level was 6.40 (4.60-10.00) $\mathrm{ng} / \mathrm{mL}$ (Table 1). cRARP was performed in 134 (56.3\%) patients, whereas RsRARP in 104 (43.7\%). The frequency of patients with the American Society of Anesthesiologists (ASA) class- 1 was higher in the cRARP group while the frequency of patients with ASA class-2 was higher in the RsRARP group $(p<0.001)$ (Table 1). No difference was found between cRARP and RsRARP in terms of PSA levels and prostate volume $(p=0.735$ and $p=0.283$, respectively). The frequency of patients with cT1c disease, patients who had ISUP-grade group (GG)-1 in prostate biopsy specimens, and patients with the clinical low-risk group were higher in the cRARP group compared to the RsRARP group ( $p=0.024, p=0.003$, and $p=0.001$, respectively) (Table 1 ).

The median surgery duration was 300 (270-360) min. The median estimated blood loss during the surgery was $50(50-100) \mathrm{mL}$. The median length of hospital stay and catheterization duration was 2 (2-3) and 7 (7-9) days, respectively. The median follow-up was 13 (6-36) months (Table 2).

pT2, рT3a, pT3b, and pT4 disease were observed in 148 (62.2\%), $59(24.8 \%), 30(12.6 \%)$, and $1(0.4 \%)$ patients, respectively.

Table 1. Preoperative clinical characteristics of patients and pathological findings of prostate biopsy specimens and comparison of patients according to surgical approach in terms of preoperative clinical characteristics and pathological findings of prostate biopsy specimens

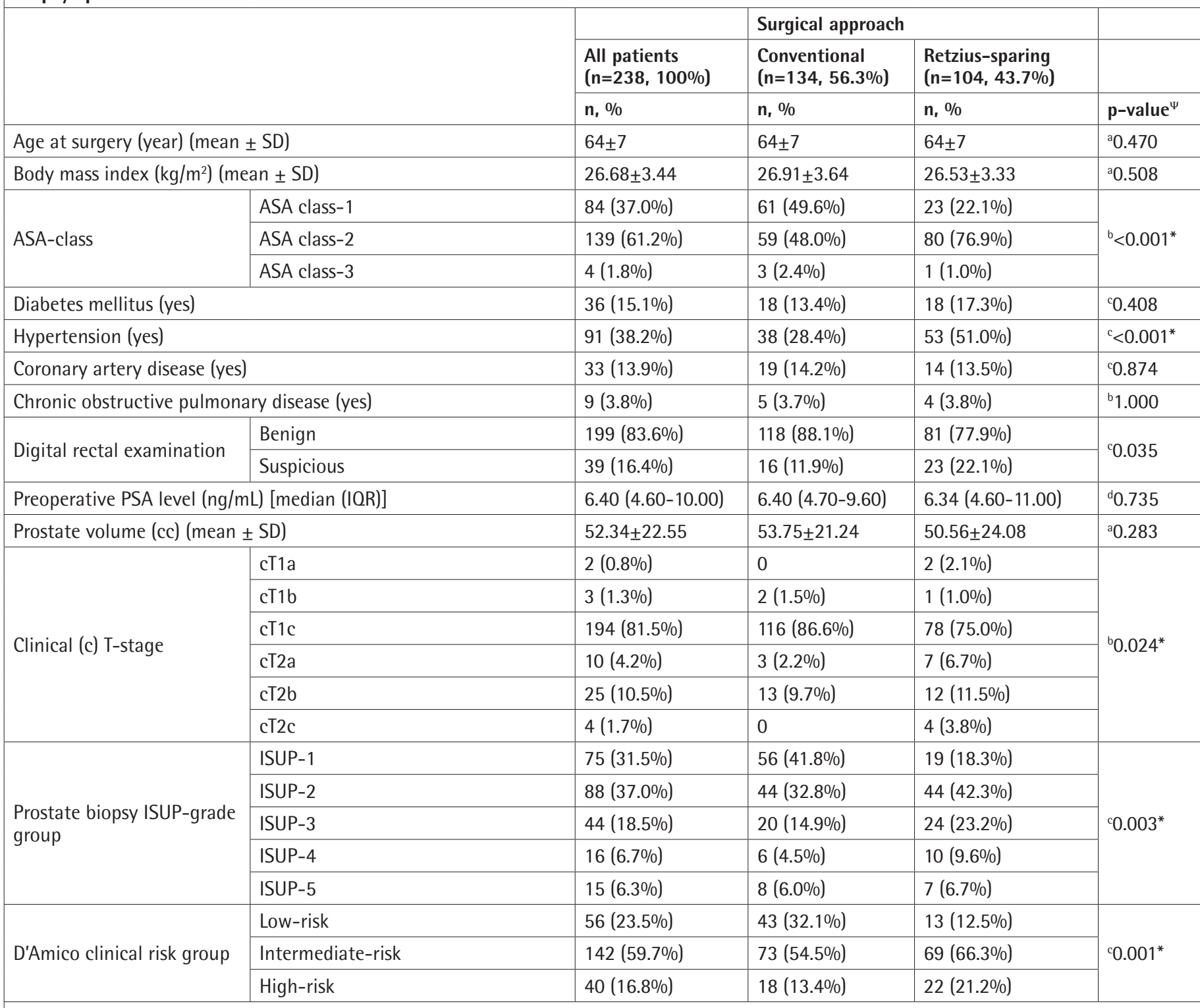

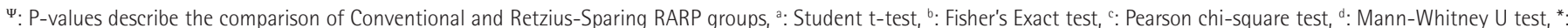

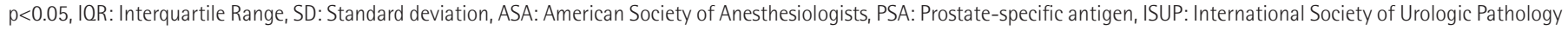


Extended pelvic lymph node dissection was performed in 139 (58.4\%) patients according to the European Association of Urology guideline recommendations (1). The mean total number of lymph nodes that are dissected in extended pelvic lymph node dissection and the median number of lymph nodes with metastatic deposits were $15 \pm 8$ and $0(0-0)$, respectively. Lymph node metastasis was observed in $13(5.5 \%)$ patients and clinically significant PCa was observed in 220 (92.4\%) patients. Positive surgical margin (PSM) was observed in 44 (18.5\%) patients (Table 2). The rate of PSM increased by the $\mathrm{pT}$ stage $(10.1 \%$ for $\mathrm{pT} 2$ and $32.6 \%$ for pT3 disease). Although not statistically significant, PSM frequency was higher in patients with pT3a and pT3b disease who underwent cRARP compared to RsRARP ( $p=0.412$ and $p=0.261$, respectively) (Table 3 ). The median number of PSM areas was 1 (1-2) in the cRARP group and $2(1-2)$ in the RsRARP group $(p=0.534)$. PSM in prostate apex was observed in $15 / 134$

Table 2. Perioperative surgical features and pathological findings of the prostatectomy specimens and the comparison of patients according to surgical approach in terms of perioperative clinical characteristics and pathological findings of the prostatectomy specimens

\begin{tabular}{|c|c|c|c|c|c|}
\hline & \multirow[b]{2}{*}{\begin{tabular}{|l} 
All patients \\
$(\mathrm{n}=238,100 \%)$
\end{tabular}} & \multicolumn{2}{|l|}{ Surgical Approach } & \multirow[b]{3}{*}{ p-value ${ }^{\Psi}$} \\
\hline & & & \multicolumn{2}{|c|}{\begin{tabular}{|l|l|} 
Conventional & Retzius-sparing \\
\end{tabular}} & \\
\hline & & $n, \%$ & $n, \%$ & $n, \%$ & \\
\hline \multicolumn{2}{|c|}{ Surgery duration (min) [median (IQR)] } & $300(270-360)$ & $330(270-390)$ & $290(240-345)$ & ${ }^{a}<0.001^{*}$ \\
\hline \multicolumn{2}{|c|}{ Estimated blood loss during surgery $(\mathrm{mL})$ [median (IQR)] } & $50(50-100)$ & $50(50-125)$ & $100(50-100)$ & ${ }^{\mathrm{a}} 0.112$ \\
\hline \multicolumn{2}{|c|}{ Length of hospital stay (day) [median (IQR)] } & $2(2-3)$ & $2(2-3)$ & $2(2-3)$ & ${ }^{\mathrm{a}} 0.774$ \\
\hline \multicolumn{2}{|c|}{ Catheterization duration (day) [median (IOR)] } & $7(7-9)$ & $7(7-8)$ & $8(7-10)$ & ${ }^{a}<0.001^{*}$ \\
\hline \multirow{5}{*}{$\begin{array}{l}\text { Prostatectomy } \\
\text { ISUP-grade } \\
\text { group }\end{array}$} & ISUP-1 & $25(10.5 \%)$ & $20(14.9 \%)$ & $5(4.8 \%)$ & \multirow{5}{*}{${ }^{\mathrm{b}} 0.003^{*}$} \\
\hline & ISUP-2 & $112(47.1 \%)$ & $67(50.0 \%)$ & $45(43.3 \%)$ & \\
\hline & ISUP-3 & $70(29.4 \%)$ & $33(24.6 \%)$ & $37(35.6 \%)$ & \\
\hline & ISUP-4 & $6(2.5 \%)$ & 0 & $6(5.8 \%)$ & \\
\hline & ISUP-5 & $25(10.5 \%)$ & $14(10.4 \%)$ & $11(10.6 \%)$ & \\
\hline \multirow{4}{*}{$\begin{array}{l}\text { Pathological (pT) } \\
\text { stage }\end{array}$} & pT2 & $148(62.2 \%)$ & $88(65.7 \%)$ & $60(57.7 \%)$ & \multirow{4}{*}{${ }^{\mathrm{c}} 0.425$} \\
\hline & pT3a & $59(24.8 \%)$ & $30(22.4 \%)$ & $29(27.9 \%)$ & \\
\hline & pT3b & $30(12.6 \%)$ & $16(11.9 \%)$ & $14(13.5 \%)$ & \\
\hline & pT4 & $1(0.4 \%)$ & 0 & $1(1.0 \%)$ & \\
\hline \multicolumn{2}{|c|}{ Extended pelvic lymph node dissection (ePLND) (yes) } & $139(58.4 \%)$ & $69(51.5 \%)$ & $70(67.3 \%)$ & ${ }^{\mathrm{b}} 0.014^{*}$ \\
\hline \multicolumn{2}{|c|}{ Total number of lymph node excised in ePLND (mean \pm SD) } & $15 \pm 8$ & $15 \pm 7$ & $15 \pm 8$ & ${ }^{\mathrm{d}} 0.840$ \\
\hline \multicolumn{2}{|c|}{ Number of metastatic lymph node [median (IQR)] } & $0(0-0)$ & $0(0-0)$ & $0(0-0)$ & ${ }^{\mathrm{a}} 0.815$ \\
\hline \multicolumn{2}{|c|}{ Lymph node metastasis (yes) } & $13(5.5 \%)$ & $6(4.5 \%)$ & $7(6.7 \%)$ & ${ }^{b} 0.792$ \\
\hline \multicolumn{2}{|c|}{ Clinically significant prostate cancer (yes) } & $220(92.4 \%)$ & $120(89.6 \%)$ & $100(96.2 \%)$ & ${ }^{b} 0.056$ \\
\hline \multicolumn{2}{|c|}{ Surgical margin (positive) } & $44(18.5 \%)$ & $27(20.1 \%)$ & $17(16.3 \%)$ & ${ }^{b} 0.453$ \\
\hline \multicolumn{2}{|c|}{ Tumor volume (mL) [median (IQR)] } & $3.20(1.50-6.50)$ & $3.00(1.24-6.00)$ & $3.25(1.90-7.00)$ & ${ }^{\mathrm{a}} 0.213$ \\
\hline \multicolumn{2}{|c|}{ Tumor volume ratio (\%) [median (IQR)] } & $7.00(2.70-14.00)$ & $6.40(2.00-13.90)$ & $7.55(3.10-14.55)$ & ${ }^{\mathrm{a}} 0.070$ \\
\hline \multicolumn{2}{|c|}{ Postoperative complication (yes) } & $13(5.5 \%)$ & $5(3.7 \%)$ & $8(7.7 \%)$ & ${ }^{\mathrm{b}} 0.182$ \\
\hline \multirow{2}{*}{$\begin{array}{l}\text { Postoperative } \\
\text { complication } \\
\text { time }\end{array}$} & Early & $12(92.3 \%)$ & $4(80.0 \%)$ & $8(100.0 \%)$ & \multirow{2}{*}{${ }^{\circ} 0.385$} \\
\hline & Late & $1(7.7 \%)$ & $1(20.0 \%)$ & 0 & \\
\hline \multirow{4}{*}{$\begin{array}{l}\text { Clavien-Dindo } \\
\text { (C-D) grade }\end{array}$} & C-D-1 & $3(1.3 \%)$ & $2(1.5 \%)$ & $1(1.0 \%)$ & \multirow{4}{*}{${ }^{\circ} 0.244$} \\
\hline & C-D-2 & $1(0.4 \%)$ & $1(0.7 \%)$ & 0 & \\
\hline & C-D-3A & $4(1.7 \%)$ & $1(0.7 \%)$ & $3(2.9 \%)$ & \\
\hline & C-D-3B & $5(2.1 \%)$ & $1(0.7 \%)$ & $4(3.8 \%)$ & \\
\hline \multirow{2}{*}{$\begin{array}{l}\text { Clavien-Dindo } \\
\text { subgroups }\end{array}$} & C-D-2 and lower & $4(1.7 \%)$ & $3(2.2 \%)$ & $1(1.0 \%)$ & \multirow{2}{*}{${ }^{\mathrm{c}} 0.077$} \\
\hline & C-D-3 and upper & $9(3.8 \%)$ & $2(1.5 \%)$ & $7(6.7 \%)$ & \\
\hline \multicolumn{2}{|c|}{ Follow-up (month) [median (IQR)] } & $13(6-36)$ & $30(12-60)$ & $8(3-13)$ & $a<0.001^{*}$ \\
\hline
\end{tabular}


(11.2\%) patients in the cRARP group and 9/104 (8.7\%) patients in the RsRARP group ( $p=0.865)$.

No intraoperative complication was observed in any patients while postoperative complications were observed in 13 (5.5\%) patients. According to C-D surgical complication classification, C-D grade-I, C-D grade-II, C-D grade-IIIa, and C-D gradeIIlb complication rates were $3(1.3 \%), 1(0.4 \%), 4(1.7 \%)$, and $5(2.1 \%)$, respectively (Table 2 ). Details of postoperative complications are summarized in Supplementary Table 1.

The comparison in terms of the perioperative clinical features revealed a significantly shorter duration of surgery in the RsRARP group $(p<0.001)$. Contrarily, no difference was found between the groups in terms of estimated blood loss ( $p=0.112)$. Additionally, no difference was found between the groups when they were compared for hospital stay duration, while the catheterization duration was longer (median 7 days vs. 8 days) in the RsRARP group ( $p=0.774$ and $p<0.001$, respectively) (Table 2).

The frequency of ISUP-GG-1 disease was higher in the cRARP group while the frequency of ISUP-GG-4 disease was higher in the RsRARP group in prostatectomy specimens $(p=0.003)$ (Table 2). However, no difference was found between the cRARP and RsRARP groups when they were compared for other pathological outcomes, such as $\mathrm{pT}$ stage, clinically significant $\mathrm{PCa}$, lymph node metastasis, number of metastatic lymph nodes, PSM, tumor volume, and tumor volume ratios ( $p>0.05$, for each) (Table 2).

No difference was found between the groups in terms of postoperative complications, C-D subgrades of surgical complications, and major complication ( $\geq C-D$ grade- 3 ) rates ( $p=0.182, p=0.244$, and $p=0.077$, respectively) (Table 2 ). The rate of $\geq \mathrm{C}$-D grade- 3 complications increased by D'Amico risk groups $(3.6 \%, 4.2 \%$, and $5.0 \%$ for low-, intermediate-, and high-risk patients, respectively), without difference between the clinical risk groups in terms of postoperative complications ( $p=0.824)$.

There was no difference between the groups in terms of BCR at months $-3,-6,-9,-12,-18,-24$, and -30 , respectively $(p=1.000$, $p=1.000, p=0.273, p=0.190, p=1.000, p=0.240$, and $p=1.000$, respectively). BCR rates of patients whose PSA levels were available in the medical records at the stated date according to surgical approach are summarized in Table 4.

\section{Discussion}

This study presented our single-center, single-surgeon, and long-term experience for cRARP and RsRARP and compared these surgical techniques in terms of perioperative clinical, pathological, and oncological outcomes. One of the main emerging findings of our study was a shorter surgical time with RsRARP. Patients in the RsRARP group had higher anesthesia risk scores according to the ASA Classification. Therefore, RsRARP becomes prominent with shorter surgery duration and similar complication rates compared to cRARP in patients with higher ASA Class scores even with higher cT stages and D'Amico clinical risk group in the preoperative evaluation, which indicate a safe surgical approach.

Recently, various RARP forms became a widely utilized approach in the surgical treatment of localized PCa (18). A large prospective, single-center, single-surgeon, consecutive case series, by Sayyid et al. (11) compared patients who underwent cRARP $(n=100)$ and RsRARP $(n=100)$ for early operative outcomes. Similar to our study results, no differences for intra- or postoperative complication rates and length of hospital stay were revealed for cRARP and RsRARP groups. Additionally, the authors revealed a significantly less console time for the RsRARP group (11). The most current systematic review, which compares cRARP and RsRARP, revealed that RsRARP was associated with shorter surgical duration (19). In this review, similar to our findings, no significant difference was reported in terms of estimated blood loss and for overall complication rates between the cRARP and RsRARP groups (19). Moreover, Phukan et al. (20) revealed similar overall and major complication (C-D grade $\geq 3$ ) rates for cRARP and RsRARP in their systematic review and meta-analysis. Contrarily, Dalela et al. (12) revealed higher postoperative complication rates for RsRARP compared to cRARP in patients with low- and intermediate-risk PCa according to the National Comprehensive Network guideline (18\% vs. 12\%, respectively).

Table 3. The distribution of surgical margin positivity frequency according to surgical approach and prostatectomy pT stage

\begin{tabular}{|c|c|c|c|c|}
\hline \multirow{3}{*}{ Pathological (p) T-stage } & & \multicolumn{2}{|l|}{ Surgical approach } & \multirow{3}{*}{ p-value } \\
\hline & & \multirow{2}{*}{$\begin{array}{l}\text { Conventional } \\
(n=134,56.3 \%)\end{array}$} & \multirow{2}{*}{\begin{tabular}{|l|}
$\begin{array}{l}\text { Retzius-sparing } \\
(n=104,43.7 \%)\end{array}$ \\
$n, \%$ \\
\end{tabular}} & \\
\hline & & & & \\
\hline pT2 $(n=148,62.2 \%)$ & Surgical Margin (positive) & $9(10.2 \%)$ & $6(10.0 \%)$ & a 0.964 \\
\hline pT3a $(n=59,24.8 \%)$ & Surgical Margin (positive) & $9(30.0 \%)$ & $6(20.7 \%)$ & ${ }^{\mathrm{a}} 0.412$ \\
\hline pT3b $(n=30,12.6 \%)$ & Surgical Margin (positive) & $9(56.3 \%)$ & $5(35.7 \%)$ & ${ }^{\mathrm{a}} 0.261$ \\
\hline
\end{tabular}




\begin{tabular}{|c|c|c|c|}
\hline \multirow{3}{*}{$\begin{array}{l}\text { Biochemical } \\
\text { Recurrence }\end{array}$} & \multicolumn{2}{|l|}{ Surgical approach } & \multirow[b]{3}{*}{ p-value } \\
\hline & $\begin{array}{l}\text { Conventional } \\
(n=134,56.3 \%)\end{array}$ & $\begin{array}{l}\text { Retzius-sparing } \\
(n=104,43.7 \%)\end{array}$ & \\
\hline & $\psi_{n}, \%$ & $\psi_{n}, \%$ & \\
\hline Month 3 (yes) & $3 / 87(3.4 \%)$ & $2 / 60(3.3 \%)$ & a1.000 \\
\hline Month 6 (yes) & $1 / 60(1.7 \%)$ & $1 / 31(3.2 \%)$ & a 1.000 \\
\hline Month 9 (yes) & $0 / 48(0 \%)$ & $1 / 18(5.6 \%)$ & ${ }^{\mathrm{a}} 0.273$ \\
\hline Month 12 (yes) & $1 / 69(1.4 \%)$ & $2 / 27(7.4 \%)$ & ${ }^{\mathrm{a}} 0.190$ \\
\hline Month 18 (yes) & $1 / 33(3.0 \%)$ & $0 / 11(0 \%)$ & a 1.000 \\
\hline Month 24 (yes) & $1 / 48(2.1 \%)$ & $1 / 7(14.3 \%)$ & ${ }^{\mathrm{a}} 0.240$ \\
\hline Month 30 (yes) & $2 / 26(7.7 \%)$ & $0 / 3(0 \%)$ & ${ }^{\mathrm{a}} 1.000$ \\
\hline Month 36 (yes) & $3 / 41(7.3 \%)$ & - & - \\
\hline Month 48 (yes) & $4 / 28(14.3 \%)$ & - & - \\
\hline Month 60 (yes) & $2 / 24(8.3 \%)$ & - & - \\
\hline Month 72 (yes) & $1 / 11(9.1 \%)$ & - & - \\
\hline Month 84 (yes) & $1 / 11(9.1 \%)$ & - & - \\
\hline Month 96 (yes) & $1 / 3(33.3 \%)$ & - & - \\
\hline Month 108 (yes) & $0 / 2(0 \%)$ & - & - \\
\hline Month 120 (yes) & $0 / 1(0 \%)$ & - & - \\
\hline Month 132 (yes) & $0 / 1(0 \%)$ & - & - \\
\hline Month 144 (yes) & $0 / 1(0 \%)$ & - & - \\
\hline \multicolumn{4}{|c|}{$\begin{array}{l}\text { a: Fisher's Exact test, } \psi \text { : The first number before the brackets indicates the patients } \\
\text { with biochemical recurrence and the second number after the brackets indicates the } \\
\text { patients whose prostate-specific antigen levels are available in medical records at the } \\
\text { stated date }\end{array}$} \\
\hline
\end{tabular}

Our study cohort revealed that neither the overall nor C-D grade of $\geq 3$ complication rates were significantly different between the groups. Complications were infrequent in both cohorts. Additionally, RsRARP may be beneficial by shortening the surgical duration in patients with high ASA Class scores. Lim et al. (21) also compared cRARP and RsRARP patients in terms of perioperative clinical and oncologic outcomes, and similar to our findings, they revealed a significantly shorter console time and oncologically safe procedure with acceptable PSM rates with RsRARP.

The status of surgical margins is important in terms of oncological control after RP. However, conflicting results were published from different institutions regarding RsRARP. Galfano et al. (14) revealed their first oncological results for RsRARP in 200 consecutive patients with a prospective, non-controlled case series study. The authors evaluated the learning-curve effect for the RsRARP outcomes. PSM for the first 100 and remaining 100 patients was reported as 22.4\% and $10.1 \%$ for pT2 disease, respectively (14). Contrarily, Dalela et al. (12) reported higher PSM for RsRARP compared to cRARP (25\% vs. $13 \%$ ). A systematic review by Checcucci et al. (19) also revealed a lower likelihood of PSM for cRARP. Level 1 evidence is rare in this context and in the first randomized controlled trial that compares CRARP and RsRARP. Menon et al. (22) revealed "non-focal" PSM as $8.3 \%$ and $11.7 \%$ for cRARP and RsRARP groups, respectively. Our study did not observe any difference between the cRARP and RsRARP groups in terms of PSM focality and apical PSM. A recent retrospective study revealed 42\% PSM with RsRARP in patients who had locally advanced PCa (13). Our study cohort revealed an overall PSM in 16.3\% of patients who underwent RsRARP, and similar to previous publications, it was $10 \%$ in patients who had pT2 disease. Performing RsRARP after an initial robotic experience in CRARP might be one of the reasons for lower PSM in the RsRARP group in our study cohort. This situation could also explain the importance of the learning-curve effect for better outcomes in robotic surgery. Increased PSM rates were reported for the pT3 stage relative to the pT2 stage (11). Contrarily, RsRARP did not alter both pT2 and pT3 PSM rates compared to cRARP in a systematic review and meta-analysis (20). However, the rate of PSM in patients with pT3 disease was lower in the RsRARP group compared to cRARP in our study cohort. This may be an important observation when taken together in patients who underwent RsRARP with statistically significantly higher cT stage, prostate biopsy ISUP-GG, and D'Amico clinical risk group in the preoperative evaluation. Our study cohort revealed lower PSM in the RsRARP group compared to the cRARP group. The level of surgical experience may explain some of the observed differences in various studies as suggested by Galfano et al. (14). Moreover, the transition between the layers of fascial planes, as we routinely performed, to adjust the limits of dissection according to the site and extent of disease may further improve the surgical margin clearance. Our study cohort included patients from all D'Amico clinical risk groups and intra-, inter-, or extrafascial dissections utilized during the operation interchangeably for PSM prevention.

Galfano et al. (14) revealed 1-year biochemical disease-free survival rates as $89 \%$ and $92 \%$ for the first and second 100 cases, respectively, in patients who underwent RsRARP. Chang et al. (23) reported similar BCR rates at 1-year for cRARP and RsRARP ( $16.7 \%$ vs. $13.3 \%$, respectively). Similarly, Dalela et al. (12) reported the probability of BCR-free survival as 0.91 vs. 0.91 for cRARP and RsRARP, respectively. Menon et al. (22) also reported similar BCR-free survival probability for two RARP techniques (0.93 vs. 0.84 , for cRARP and RsRARP, respectively) in patients with low-intermediate PCa at 12 months. Our study revealed quite lower BCR rates in both CRARP and RsRARP groups compared to the aforementioned studies at 12 months.

\section{Study Limitations}

This study has some limitations. The major limitation is its retrospective nature, which might have introduced a selection 
bias for an accurate comparison of each group. Additionally, long-term follow-up for PSA levels and BCR status is lacking for some patients, which limits the validity of long-term-oncological outcomes. Currently, the collection of data for both long-term functional and oncological outcomes of patients is an ongoing project at our institution. However, two key strengths of the present study that are worth mentioning include the presence of a control group, which includes the patients who underwent cRARP, and performance of all surgeries by the same surgeon in both groups, which eliminate most of the operator-related variables. Another important aspect is the inclusion of patients with all D'Amico clinical risk groups, which reflects our routine Uro-oncology practice.

\section{Conclusion}

The present study suggests that RsRARP can be safely performed with similar oncological efficacy and complication rates with a significantly shorter surgical time compared to cRARP even in patients with higher ASA Class scores, higher cT stages, and D'Amico clinical risk group. Further well-designed, large-scale, multi-center, prospective studies are required to confirm these findings.

\section{Ethics}

Ethics Committee Approval: The Local Institutional Ethics Committee (IRB No: 2020-26/09) approved this study and all steps were planned and conducted following the Declaration of Helsinki and its later amendments.

Informed Consent: Written informed consent on admittance to the hospital was obtained from all individuals, which permitted the use of respective medical information in clinical studies.

Peer-review: Externally and internally peer-reviewed.

\section{Authorship Contributions}

Surgical and Medical Practices: Y.S., L.T., Concept: B.Ö., L.T., Design: B.Ö., L.T., Data Collection or Processing: N.K., M.B.Ö., H.D., Analysis or Interpretation: N.K., M.B.Ö., Y.S., L.T., Literature Search: N.K., Writing: N.K., M.B.Ö., L.T.

Conflict of Interest: No conflict of interest was declared by the authors.

Financial Disclosure: The authors declare that they have no relevant financial.

\section{References}

1. Mottet $N$, van den Bergh RCN, Briers E, Cornford P, De Santis M, Fanti $S$, Gillessen S, Grummet J, Henry AM, Lam TB, Mason MD, van der Poel HG, van der Kwast TH, Rouvière O, Schoots I, Tilki D, Wiegel T. EAU - ESTRO ESUR - SIOG Guidelines on Prostate Cancer 2020. European Association of Urology Guidelines. 2020 Edition., Vol presented at the EAU Annual
Congress Amsterdam 2020. Arnhem, The Netherlands, European Association of Urology Guidelines Office, 2020.

2. Abbou CC, Hoznek A, Salomon L, Lobontiu A, Saint F, Cicco A, Antiphon $P$, Chopin D. Prostatectomie radicale laparoscopique réalisée à distance par robot. A propos d'un cas [Remote laparoscopic radical prostatectomy carried out with a robot. Report of a case]. Prog Urol 2000;10:520-523.

3. Binder J, Kramer W. Robotically-assisted laparoscopic radical prostatectomy. BJU Int 2001;87:408-410.

4. Yaxley JW, Coughlin GD, Chambers SK, Occhipinti S, Samaratunga $H$, Zajdlewicz L, Dunglison N, Carter R, Williams S, Payton DJ, Perry-Keene J, Lavin MF, Gardiner RA. Robot-assisted laparoscopic prostatectomy versus open radical retropubic prostatectomy: early outcomes from a randomised controlled phase 3 study. Lancet 2016;388:1057-1066.

5. Ilic D, Evans SM, Allan CA, Jung JH, Murphy D, Frydenberg M. Laparoscopic and robotic-assisted versus open radical prostatectomy for the treatment of localised prostate cancer. Cochrane Database Syst Rev 2017;9:CD009625.

6. Tewari A, Peabody J, Sarle R, Balakrishnan G, Hemal A, Shrivastava A, Menon M. Technique of da Vinci robot-assisted anatomic radical prostatectomy. Urology 2002;60:569-572.

7. Rocco F, Carmignani L, Acquati P, Gadda F, Dell'Orto P, Rocco B, Bozzini $G$, Gazzano G, Morabito A. Restoration of posterior aspect of rhabdosphincter shortens continence time after radical retropubic prostatectomy. J Urol 2006;175:2201-2206.

8. Patel VR, Coelho RF, Palmer KJ, Rocco B. Periurethral suspension stitch during robot-assisted laparoscopic radical prostatectomy: description of the technique and continence outcomes. Eur Urol 2009;56:472-478.

9. Menon M, Shrivastava A, Bhandari M, Satyanarayana R, Siva S, Agarwal PK. Vattikuti Institute prostatectomy: technical modifications in 2009. Eur Urol 2009;56:89-96.

10. Galfano A, Ascione A, Grimaldi S, Petralia G, Strada E, Bocciardi AM. A new anatomic approach for robot-assisted laparoscopic prostatectomy: a feasibility study for completely intrafascial surgery. Eur Urol 2010;58:457-461.

11. Sayyid RK, Simpson WG, Lu C, Terris MK, Klaassen Z, Madi R. Retzius-Sparing Robotic-Assisted Laparoscopic Radical Prostatectomy: A Safe Surgical Technique with Superior Continence Outcomes. J Endourol 2017;31:12441250.

12. Dalela $D$, Jeong $W$, Prasad $M A$, Sood $A$, Abdollah $F$, Diaz $M$, Karabon $P$, Sammon J, Jamil M, Baize B, Simone A, Menon M. A Pragmatic Randomized Controlled Trial Examining the Impact of the Retzius-sparing Approach on Early Urinary Continence Recovery After Robot-assisted Radical Prostatectomy. Eur Urol 2017;72:677-685.

13. Nyarangi-Dix JN, Görtz M, Gradinarov G, Hofer L, Schütz V, Gasch C, Radtke $J P$, Hohenfellner M. Retzius-sparing robot-assisted laparoscopic radical prostatectomy: functional and early oncologic results in aggressive and locally advanced prostate cancer. BMC Urol 2019;19:113.

14. Galfano A, Di Trapani D, Sozzi F, Strada E, Petralia G, Bramerio M, Ascione A, Gambacorta M, Bocciardi AM. Beyond the learning curve of the Retziussparing approach for robot-assisted laparoscopic radical prostatectomy: oncologic and functional results of the first 200 patients with $\geq 1$ year of follow-up. Eur Urol 2013;64:974-980.

15. Dindo D, Clavien PA. What is a surgical complication? World J Surg 2008;32:939-941.

16. Epstein Jl, Walsh PC, Carmichael M, Brendler CB. Pathologic and clinical findings to predict tumor extent of nonpalpable (stage T1c) prostate cancer. JAMA 1994;271:368-374.

17. Epstein JI, Egevad L, Amin MB, Delahunt B, Srigley JR, Humphrey PA; Grading Committee. The 2014 International Society of Urological Pathology (ISUP) Consensus Conference on Gleason Grading of Prostatic Carcinoma: Definition of Grading Patterns and Proposal for a New Grading System. Am J Surg Pathol 2016;40:244-252. 
18. Agarwal G, Valderrama O, Luchey AM, Pow-Sang JM. Robotic-Assisted Laparoscopic Radical Prostatectomy. Cancer Control 2015;22:283-290.

19. Checcucci E, Veccia A, Fiori C, Amparore D, Manfredi M, Di Dio M, Morra I, Galfano A, Autorino R, Bocciardi AM, Dasgupta P, Porpiglia F. Retziussparing robot-assisted radical prostatectomy vs the standard approach: a systematic review and analysis of comparative outcomes. BJU Int 2020;125:8-16.

20. Phukan C, Mclean A, Nambiar A, Mukherjee A, Somani B, Krishnamoorthy R, Sridhar A, Rajan P, Sooriakumaran P, Rai BP. Retzius sparing robotic assisted radical prostatectomy vs. conventional robotic assisted radical prostatectomy: a systematic review and meta-analysis. World J Urol 2020;38:1123-1134
21. Lim SK, Kim KH, Shin TY, Han WK, Chung BH, Hong SJ, Choi YD, Rha $\mathrm{KH}$. Retzius-sparing robot-assisted laparoscopic radical prostatectomy: combining the best of retropubic and perineal approaches. BJU Int 2014;114:236-244.

22. Menon $M$, Dalela $D$, Jamil $M$, Diaz $M$, Tallman $C$, Abdollah $F$, Sood $A$, Lehtola L, Miller D, Jeong W. Functional Recovery, Oncologic Outcomes and Postoperative Complications after Robot-Assisted Radical Prostatectomy: An Evidence-Based Analysis Comparing the Retzius Sparing and Standard Approaches. J Urol 2018;199:1210-1217.

23. Chang LW, Hung SC, Hu JC, Chiu KY. Retzius-sparing Robotic-assisted Radical Prostatectomy Associated with Less Bladder Neck Descent and Better Early Continence Outcome. Anticancer Res 2018;38:345-351.

\begin{tabular}{|l|l|l|l|}
\hline \multicolumn{3}{|c|}{ Supplementary Table 1. Details of overall complications according to Clavien-Dindo surgical complication classification } \\
\hline $\begin{array}{l}\text { Grade-I } \\
(\mathbf{n = 3}, \mathbf{1 . 3} \%)\end{array}$ & $\begin{array}{l}\text { Grade-II } \\
(\mathbf{n}=\mathbf{1}, \mathbf{0 . 4} \%)\end{array}$ & $\begin{array}{l}\text { Grade-IIla } \\
(\mathbf{n}=\mathbf{4}, \mathbf{1 . 7} \%)\end{array}$ & $\begin{array}{l}\text { Grade-IIIb } \\
(\mathbf{n}=5, \mathbf{2 . 1} \%)\end{array}$ \\
\hline $\begin{array}{l}\text { Conservatively managed } \\
\text { hematuria } \\
{[1(0.4 \%)]}\end{array}$ & $\begin{array}{l}\text { Postoperative fever treated } \\
\text { with antibiotic }\end{array}$ & $\begin{array}{l}\text { Delayed anastomosis healing and re- } \\
\text { catheterization under local anesthesia } \\
{[2(0.8 \%)]}\end{array}$ & $\begin{array}{l}\text { Bleeding required re-operation } \\
{[2(0.8 \%)]}\end{array}$ \\
\hline $\begin{array}{l}\text { Conservatively managed delayed } \\
\text { anastomosis healing } \\
{[1(0.4 \%)]}\end{array}$ & - & $\begin{array}{l}\text { Percutaneous abscess drainage under local } \\
\text { anesthesia } \\
{[1(0.4 \%)]}\end{array}$ & $\begin{array}{l}\text { Re-operation for anastomosis } \\
\text { repair } \\
{[2(0.8 \%)]}\end{array}$ \\
\hline $\begin{array}{l}\text { Urinary retention required re- } \\
\text { catheterization } \\
{[1(0.4 \%)]}\end{array}$ & - & $\begin{array}{l}\text { Percutaneous intra-abdominal urine } \\
\text { drainage under local anesthesia } \\
{[1(0.4 \%)]}\end{array}$ & $\begin{array}{l}\text { Hernioraphy due to incisional } \\
\text { hernia } \\
{[1(0.4 \%)]}\end{array}$ \\
\hline
\end{tabular}

